\title{
Atypical MR findings in Wilson's disease: pronounced lesions in the dentate nucleus causing tremor
}

A

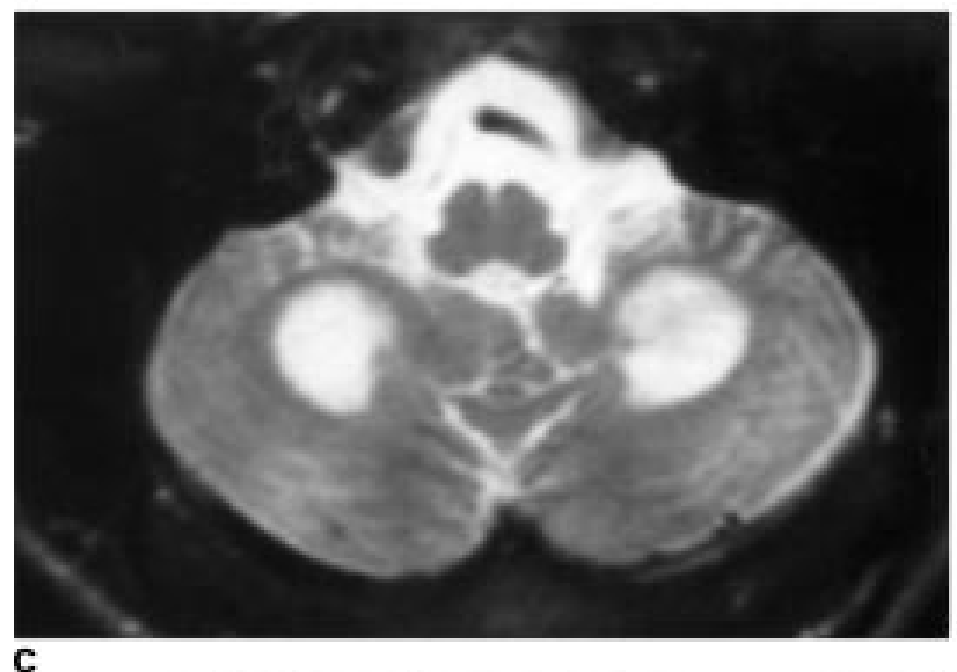

C

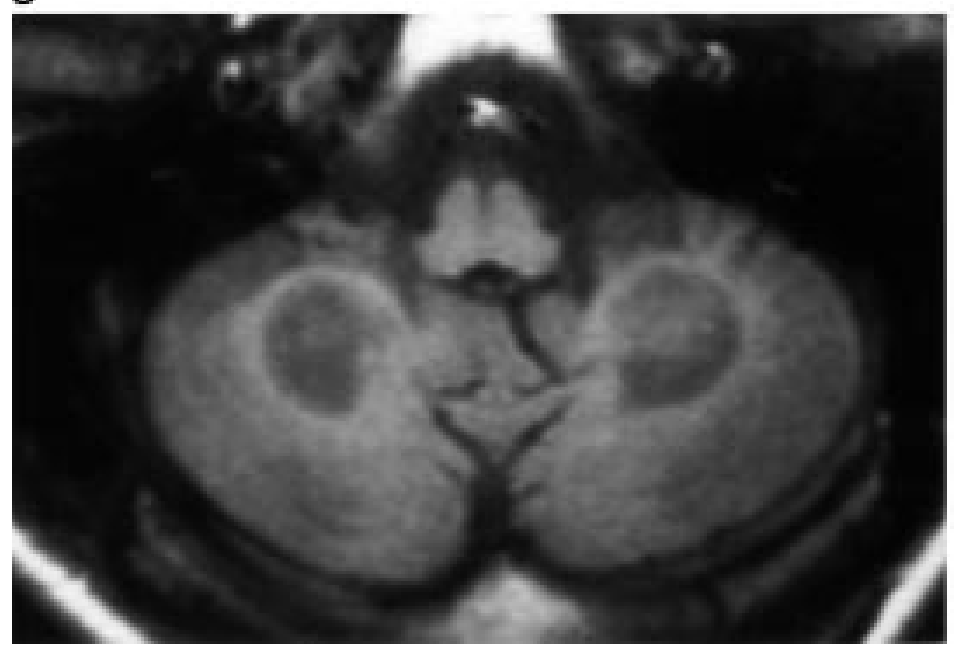

B

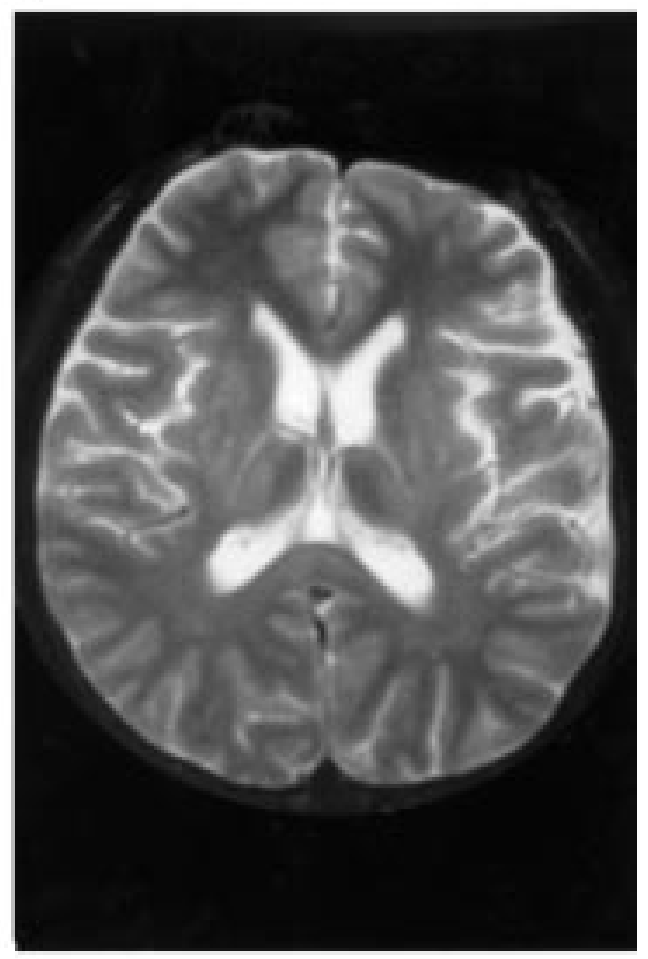

A 20 year old Japanese man noticed progressive tremulous movements of his left hand when using it, over one year. Neurological examination showed slurred speech, postural and action tremor of his left hand, slight spasticity of his lower limbs, and slight incoordination of both arms and legs. Slit lamp examination of his cornea confirmed Kayser-Fleischer rings. Serum copper concentration was $11 \mathrm{mg} / \mathrm{dl}$ (normal: $80-140 \mathrm{mg} / \mathrm{ml}$ ), caeruloplasmin concentration was $6 \mathrm{ng} / \mathrm{dl}$ (normal: 17-37 ng/dl), and urinary copper excretion was $681 \mu \mathrm{g} / \mathrm{dl}$ (normal $<20 \mu \mathrm{g} / \mathrm{dl}$ ). A liver biopsy confirmed the diagnosis of Wilson's disease with increased amounts of copper deposition $(280 \mu \mathrm{g} / \mathrm{g}$ dry weight). Brain CT showed bilateral low absorption of the dentate nuclei in the cerebellum. Brain MRI disclosed predominantly increased signal intensity lesions on T2 weighed images bilaterally in the dentate nuclei (figure, A), compared with the lenticular, caudate, and thalamic nuclei (figure, B). The dentate nuclei showed distinctly decreased signal intensity lesions on T1 weighed images (figure, C), suggestive of cavitation in these regions. Although it was considered that lesions of the dentatorubrothalamic tract cause the postural and action tremor, the clear cut demonstration of dentate nuclei lesions in Wilson's disease herein presented is atypical. ${ }^{12}$

$$
\begin{array}{r}
\text { TOHRU MATSUURA } \\
\text { HIDENAO SASAKI } \\
\text { KUNIO TASHIRO } \\
\text { Department of Neurology, } \\
\text { Hokkaido University School of Medicine, } \\
\text { Sapporo, Fapan }
\end{array}
$$

Correspondence to: Dr Tohru Matsuura, Department of Neurology, Hokkaido University School of Medicine, Kita-14, Nishi-5, Kita-ku, Sapporo 060, Japan. Telephone +81 (11) 716-1161 (extension 6028); fax +81 (11) 700-5356.

1 Thomas KA, Aquilonius SM, Bergstrom K, Westemark K. Magnetic resonance imaging of the brain in Wilson's disease. Neuroradiology 1993;35:134-41. 2 Nazer H, Brismar J, Al-Kawi MZ, Gunasekaran TS, Jorulf KH. Magnetic resonance imaging of the brain in Wilson's disease. Neuroradiology 1993;35:130-3. 